\title{
EFFECT OF ALUMINUM CONTENT ON THE HARDNESS AND MACHINABILITY OF BRASS ALLOY USED IN OXYGEN CYLINDER VALVE
}

\author{
Hassanein Ibraheem Khalaf \\ hassanein.khalaf@uobasrah.edu.iq \\ University of Basrah-College of Engineering-Department of Mechanical Engineering
}

\begin{abstract}
There is high consumption of oxygen cylinder valves due to incorrect application of valves, therefore, this research will study the possibility to modify Brass alloy that used to produce cylinder valves and reduce their erosion that happens under the use of valve. The main type of brass that used to make cylinder valve is CW713R which contained aluminum with percentage of 1.3-2.3\% with hardness of $174 \mathrm{HV}$. Therefore, the effect of aluminum element on the properties of brass alloy will study to find the best and the optimum percentages that can be added to improve the hardness and machinability of cylinder valve. Brass scrap was melted using oil fire furnace and aluminum element was added before it cast. Then, the melting liquid was poured on steel die casting mold. The result shows that the hardness Brass cylinder valve was increased by increasing the percentage of aluminum element. It is raised from 206 to $605 \mathrm{HV}$. But when the percentage of aluminum reached 10 $\%$ the Brass material becomes brittle and difficult to machine. The best percentage of aluminum that can be added to brass alloy lies in the range of $2.5-5 \%$.
\end{abstract}

Keywords: Brass, Aluminum, Hardness, Cylinder valve, Machinability

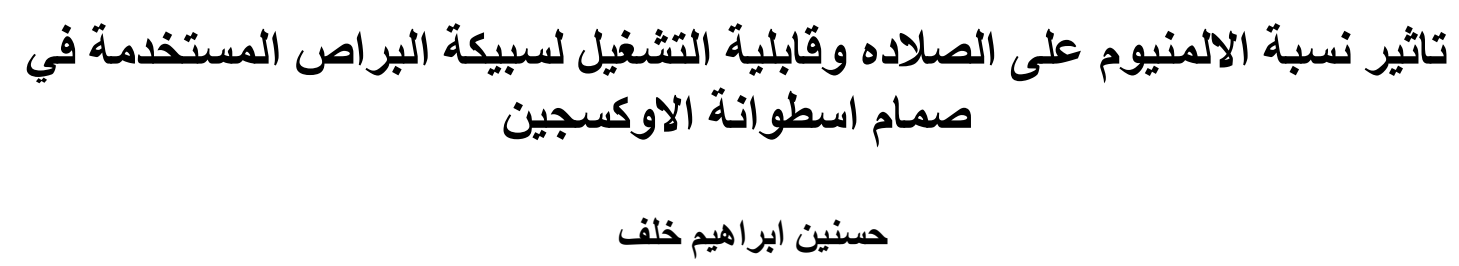

الخلاصة

بسبب عدم الاستخدام الصحيح للصمامات لوحظ هنالك استهلاك كبير في صمامات قناني الاوكسجين.لذلانك هذا البحث

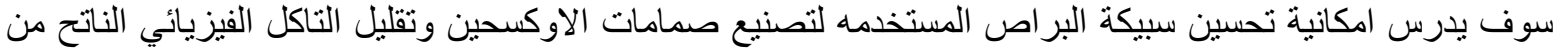

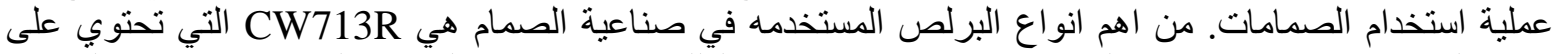

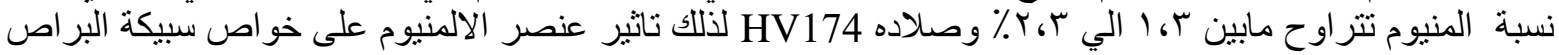

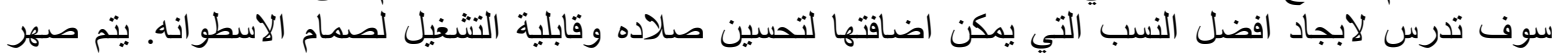

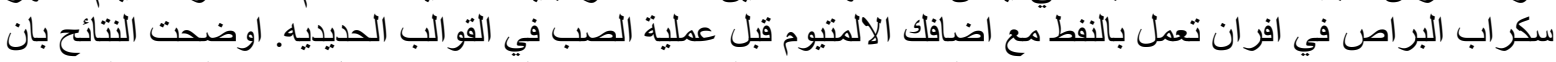

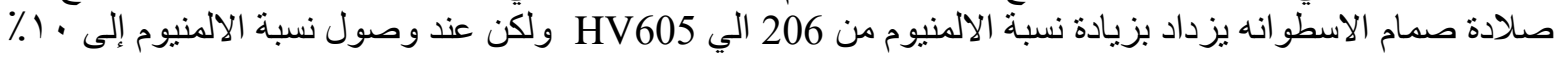

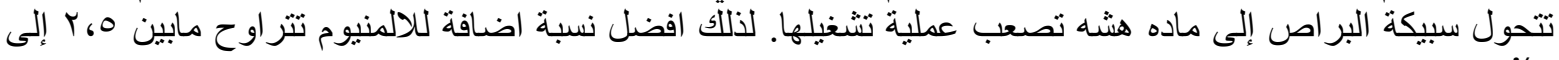




\section{INTRODUCTION}

Brass is defined as an alloy prepared from copper and zinc with a small amount of additional metals such as iron, lead, tin and aluminum to improve their properties. The higher percentage of copper leads to increase ductility of brass and the higher percentage of zinc lead to increase the hardness, strength and brittleness of brass Sujit et al. (2015), Nowosielski et al. (2001) and Kommel et al. (2007). Many types of brass alloys can be used in industrial application due to their properties. Different alloying elements added to brass alloys to improve their mechanical properties. Brass has good strength, ductility and corrosion resistance therefore it is applied to made numerous parts such as valves and fittings Sujit et al. (2015), Nowosielski et al. (2001), Kommel et al. (2007) and A Arigraha et al (2017). Brasses with low and high percentages of copper can be made from electrically refined copper and recycling copper alloy to minimize the amount of other materials. The pure brass alloy content $85 \%$ copper and $15 \%$ zinc. On the other hand, other brass alloys can be content 35\% - 45\% zinc Sujit et al. (2015), Nowosielski et al. (2001), Kommel et al. (2007), A Arigraha et al (2017) and Rajab et al (2014). Aluminum has the highest influence in increasing the hardness and strength of brass alloys because of their microstructure and ductility. Also, corrosion resistance is improved by the self-healing oxide film aluminum confers Rajab et al (2014)..

The main types of brass alloys that can be used to manufacture oxygen cylinder valve include C36000, C46400, C48500 and C68700 brass. C36000 is a free machining brass is suited for high-speed machining operations with its superior machinability, thread rolling and knurling characteristics which have good resistance to corrosion. However, C46400 is a Nava brass is composed of $60 \%$ copper, $39.2 \%$ zinc which can be considered a typical brass alloy with the duplex alpha + beta structure. It has good strength and rigidity, high corrosion resistance to seawater, high resistance to wear, fatigue, galling, and stress corrosion cracking. On the other hand, C48500 is a naval brass with high leaded which obtained by added lead which are responsible for machinability, castability and corrosion resistance. It has high ductility and high impact strength with good creep resistance. Finally, C68700 is aluminum brass alloy that called arsenical that applied in the industrial field as condenser tube, evaporator tubes, heat exchanger tubes M. Kondracki et al (2003) and Muna et al (2001).Different alloying elements that include lead, tin, silicon, arsenic, iron, manganese, nickel and aluminum alloys will be added to brass to improve their properties. Lead with percentage up to $3 \%$ added to brass to provide free machining properties without any effect on their corrosion resistance. On the other hand, tin with percentage of $1 \%$ was added to improve the corrosion resistance for brass. Moreover, silicon added to increase the strength and wear resistance of brass. Furthermore, arsenic is added with small amounts to provide protection against dezincification corrosion. Also, iron and manganese added to increase the hardness, tensile strength and reduce the ductility. On the other hand, hardness and strength can be improved by added Nickel without any significant effect on ductility Muna et al (2001) and James (2013). A Arisgraha et al (2014), studied the effects of aluminum addition on the characteristics of $\mathrm{Cu}-28 \mathrm{Zn}$ brass produced by gravity casting. They found that add of 1.9 and $5.7 \mathrm{wt} . \% \mathrm{Al}$ increased the tensile strength of $\mathrm{Cu}-28 \mathrm{Zn}$ alloy from $209 \mathrm{MPa}$ to 415.7 and $545.25 \mathrm{MPa}$, respectively. Also, hardness increased from $53 \mathrm{VH}$ to 77.46 and $356.23 \mathrm{VH}$, respectively. Zhuangzhuang et al (2020). with his colleagues have been considered the effect of aluminum element on the microstructure and the mechanical properties of brass as well as wear performances of a newly developed $\mathrm{Ni}-\mathrm{Si}$-containing complex brass. Results presented that with increasing the percentage of aluminum up to $3 \%$, the mechanical properties of brass will increase. In addition, it shows the best solidification microstructure with uniform distribution phase and wear resistance. 
Aluminum with percentage in the range of 1.5 to $8 \%$ added to brass to increase its hardness and modulus elasticity. It will make brass easily worked for any purpose. However, brass containing $8 \%$ of aluminum has the valuable property of being but slightly affected by acids or gases. A larger percentage of aluminum makes the brass brittle M. Kondracki et al (2003) \& Zhuangzhuang et al (2020). The aim of this research is to study the effect of aluminum element on the properties of oxygen cylinder valve to improve its mechanical properties and find the best percentage of aluminum that should be added to brass alloy.

\section{EXPERIMENTAL WORK}

\section{Sample Preparation by Casting Process}

The mould used to cast melting brass in casting process is manufacturing from carbon steel plates. The mould contains two parts with thickness of $50 \mathrm{~mm}$ for each one and dimension of $250 \times 300 \mathrm{~mm}$ as shown in figures (1) and (2) to produce cylinder valve shape as shown in figure 3 .

\section{Melting Procedure}

Raw materials that used to make new brass alloy with aluminum element include scrap of brass and copper pipes with aluminum scrap. They cut to be suitable for melting in furnace and added to furnace with percentage of aluminum as shown in figure (1). The melting process was done by oil crucible furnace with temperature of $1250{ }^{\circ} \mathrm{C}$ which takes 50 minutes to melt scraps. Then, the melting liquid was transfer by crucible and pour into steel mold. The pouring operation was relatively slow cast to avoid any defects that might be happened like air gaps and porosity. It is left for $20 \mathrm{~min}$. for cooling inside the mold then opened the mold to get the casting valves. Five heats with different percentages of aluminum were done.

\section{RESULTS AND DISCUSSION}

\section{Casting Shapes}

Figures (4) and (5) show the shape of casting valves that cast with different percentages of aluminum element.

\section{Chemical Composition}

The melting process for brass alloy and aluminum leads to losses of Al\% which happened because the present white layer of $\mathrm{Al}_{2} \mathrm{O}_{3}$ will evaporate during melting operation. The losses of aluminum element that happened during the melting process are equal to $40 \%$ as shown in table(2). The main chemical composition of casting brass alloy after melting and casting is shown in table 3 which have been exanimated by using spectrum analyzer device model Spectrotest TXC25 that available in Mechanical Engineering department at university of Basrah.

\section{Hardness}

The hardness was increased by increasing the percentage of aluminum element to brass alloy. It was increased to be $605 \mathrm{HV}$ when the percentage of $\mathrm{Al}$ equal to $10 \%$ as shown in table (4) and figure(6). This is because the refinement of grains and reduce their size with more uniform distribution which agree with the results found by Rajab et al (2014). 


\section{Machinability}

Machinability is defined as an indicator of one engineering material how easy or difficult to be machined using a cutting tool to achieve an acceptable surface finish, which could be considered as a material property. The main factors that affecting machinability include microstructure, grain size, heat treat condition, chemical composition, fabrication methods, hardness, yield and tensile strength of the work piece. Table (5) shows the state of each percentage of aluminum and its effect of the machinability of samples or valves. When the percentage of aluminum increase the hardness increased too which led to difficulty to operate and machine the casting valve. Therefore, the percentage of aluminum is $2.5 \%$ and can be increased to be $7.5 \%$ as maximum percentage of aluminum that can be added to brass casting.

\section{Microstructure}

Samples were cutting to prepare by wet grinding using emery paper grades in the range of 320, 400, 600, 800, 1000, 1200, 1500 and 2000 grit (sic)) with water. Then, samples were polished by using alumina powder suspended solution with particle size of $0.5 \mu \mathrm{m}$, and napless cloth. After that samples were cleaned with water. Finally, etching was done by using $2.5 \% \mathrm{HNO}_{3}, 1.5 \% \mathrm{HCl}, 1 \% \mathrm{HF}$ and $95 \% \mathrm{H}_{2} \mathrm{O}$ for 15 seconds. The microstructure of samples was done by using an optical microscope and digital camera as shown in figures 7 and 8.

\section{CONCLUSIONS}

1. The best percentages of aluminum can be used to produce suitable brass alloy are 2.5 and $5 \% \mathrm{Al}$ because it has good hardness and machinability.

2. Aluminum added with percentage of $10 \%$ is not good for manufacturing cylinder valves because the metal will be hard and brittle. It is not easy to machine in all types of machines which can be cut and machine by grinding machine only.

3. There is a gradual increase in the hardness with increasing the percentage of added aluminum.

\section{Acknowledgment}

This work was supported and funded by University of Basrah, College of Engineering, Department of Mechanical Engineering.

Table(1) Percentage of Aluminum element added to cast brass alloys

\begin{tabular}{|c|c|c|c|c|c|}
\hline Heat No. & $\mathbf{1}$ & $\mathbf{2}$ & $\mathbf{3}$ & $\mathbf{4}$ & $\mathbf{5}$ \\
\hline Al wt\% & 0 & 2.5 & 5 & 7.5 & 10 \\
\hline
\end{tabular}

Table(2) Losses of aluminum element after melting with brass alloys

\begin{tabular}{|c|c|c|c|c|c|}
\hline Heat No. & $\mathbf{1}$ & $\mathbf{2}$ & $\mathbf{3}$ & $\mathbf{4}$ & $\mathbf{5}$ \\
\hline Al\% before melting & 0 & 2.5 & 5 & 7.5 & 10 \\
\hline Al\% after melting & 0 & 1.38 & 3.02 & 5.82 & 7.76 \\
\hline
\end{tabular}

Table(3) Chemical analysis of casting brass alloys

\begin{tabular}{|c|c|c|c|}
\hline \multirow{2}{*}{ Heat No. } & \multicolumn{3}{|c|}{ Chemical Composition wt \% } \\
\cline { 2 - 4 } & $\mathrm{Al} \%$ & $\mathrm{Zn} \%$ & $\mathrm{Cu} \%$ \\
\hline $\mathbf{1}$ & 0 & 30.86 & 61.38 \\
\hline $\mathbf{2}$ & 7.76 & 28.50 & 62.17 \\
\hline $\mathbf{3}$ & 5.82 & 35.28 & 60.93 \\
\hline $\mathbf{4}$ & 3.02 & 28.81 & 66.60 \\
\hline $\mathbf{5}$ & 1.38 & \multicolumn{2}{c}{} \\
\hline
\end{tabular}


Table(4) Hardness of casting brass alloys

\begin{tabular}{|c|c|c|}
\hline Heat No. & Al \% & Hardness HV $\left.\mathbf{( k g f} / \mathbf{m m}^{2}\right)$ \\
\hline 1 & 0 & 206 \\
\hline 2 & 2.5 & 260.7 \\
\hline 3 & 5 & 340.5 \\
\hline 4 & 7.5 & 394.9 \\
\hline 5 & 10 & 605.4 \\
\hline
\end{tabular}

Table(5) Machinability of casting brass alloys

\begin{tabular}{|c|l|}
\hline Al \% & \multicolumn{1}{c|}{ Machinability } \\
\hline 2.5 & The best sample in operating ability. \\
\hline 5 & It can be operating in all machines. \\
\hline 7.5 & It can be operating in all machines. \\
\hline 10 & Could not be operating, but only in grinding machines. \\
\hline
\end{tabular}

Upper half of mould

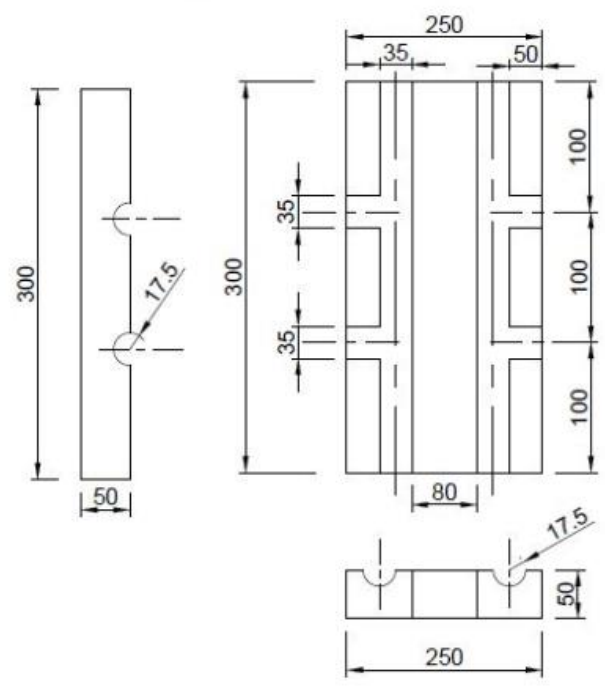

Lower half of mould

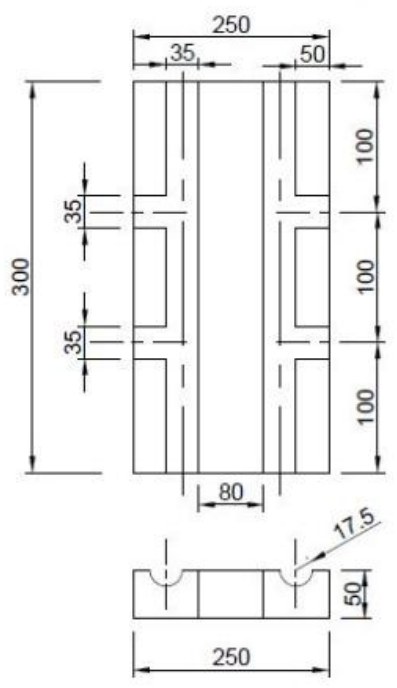

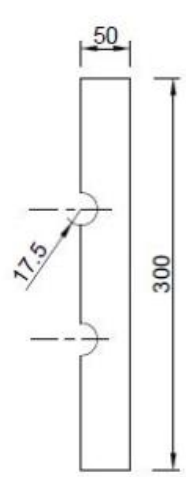

Fig. (1) Dimension of Carbon steel Mold
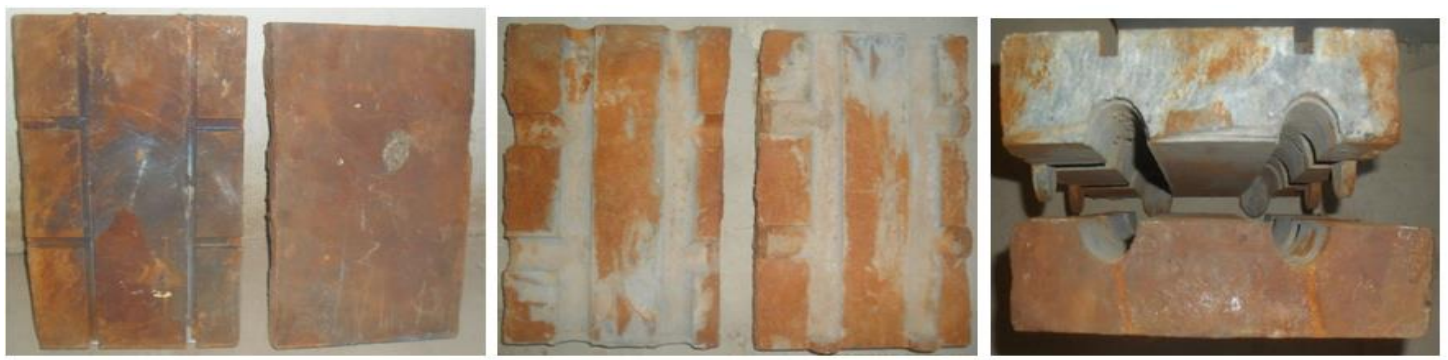

Fig. (2) Carbon steel Mold 


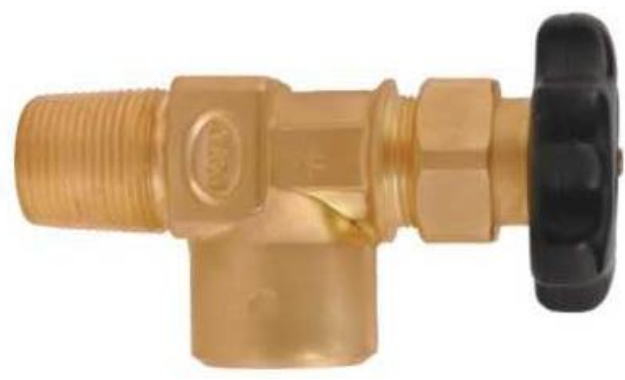

Fig. (3) Oxygen cylinder valve [10]

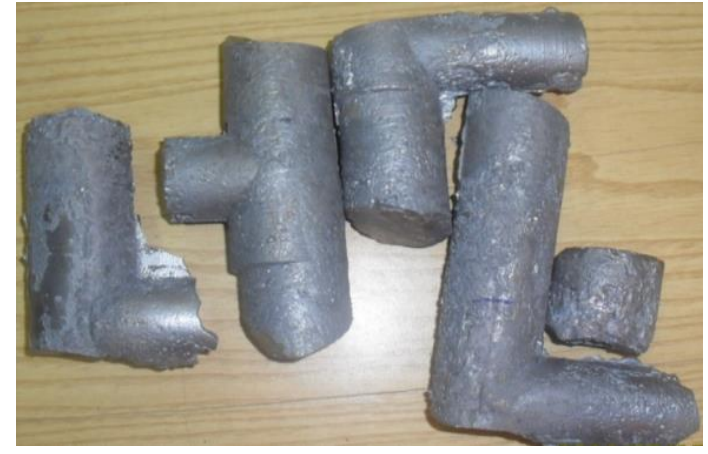

Heat No. 1

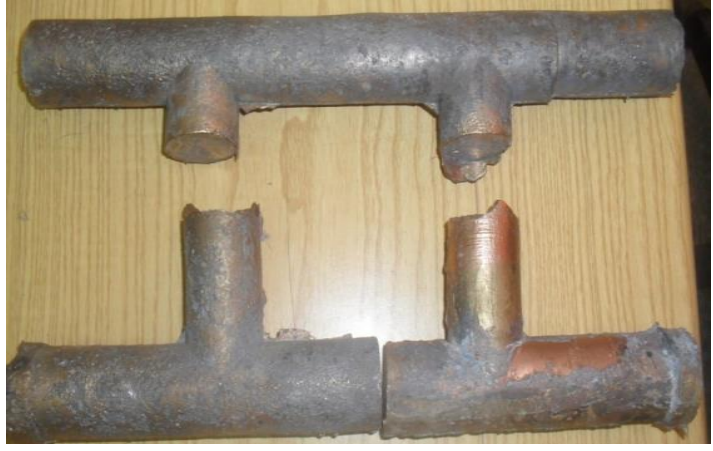

Heat No. 2

Fig. (4) Shapes of casting valves for heats number 1 and 2

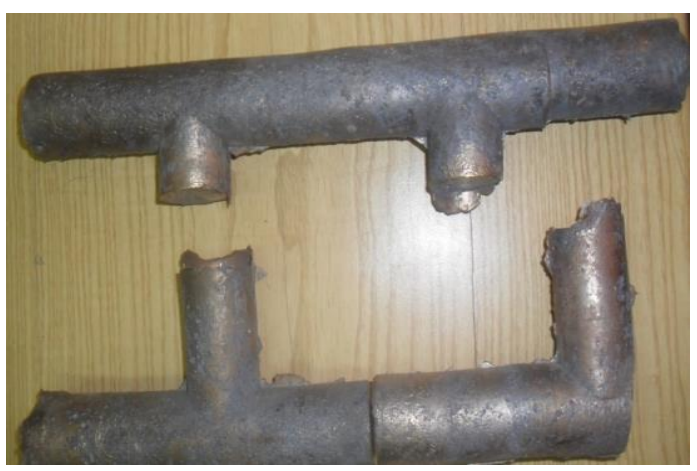

Heat No. 3

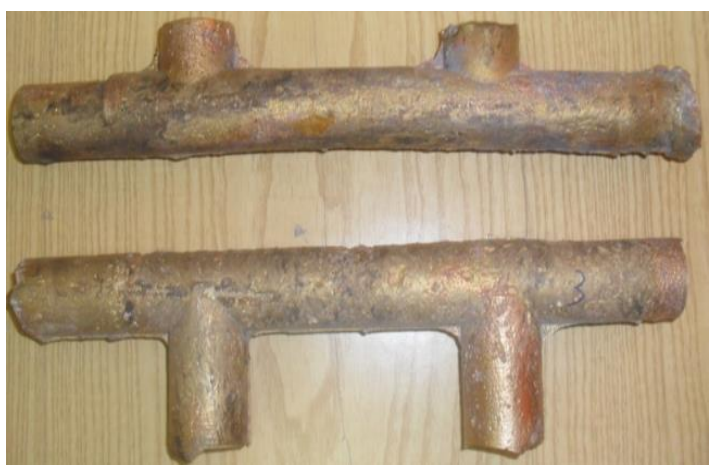

Heat No. 4

Fig. (5) Shapes of casting valves for heats number 3 and 4 


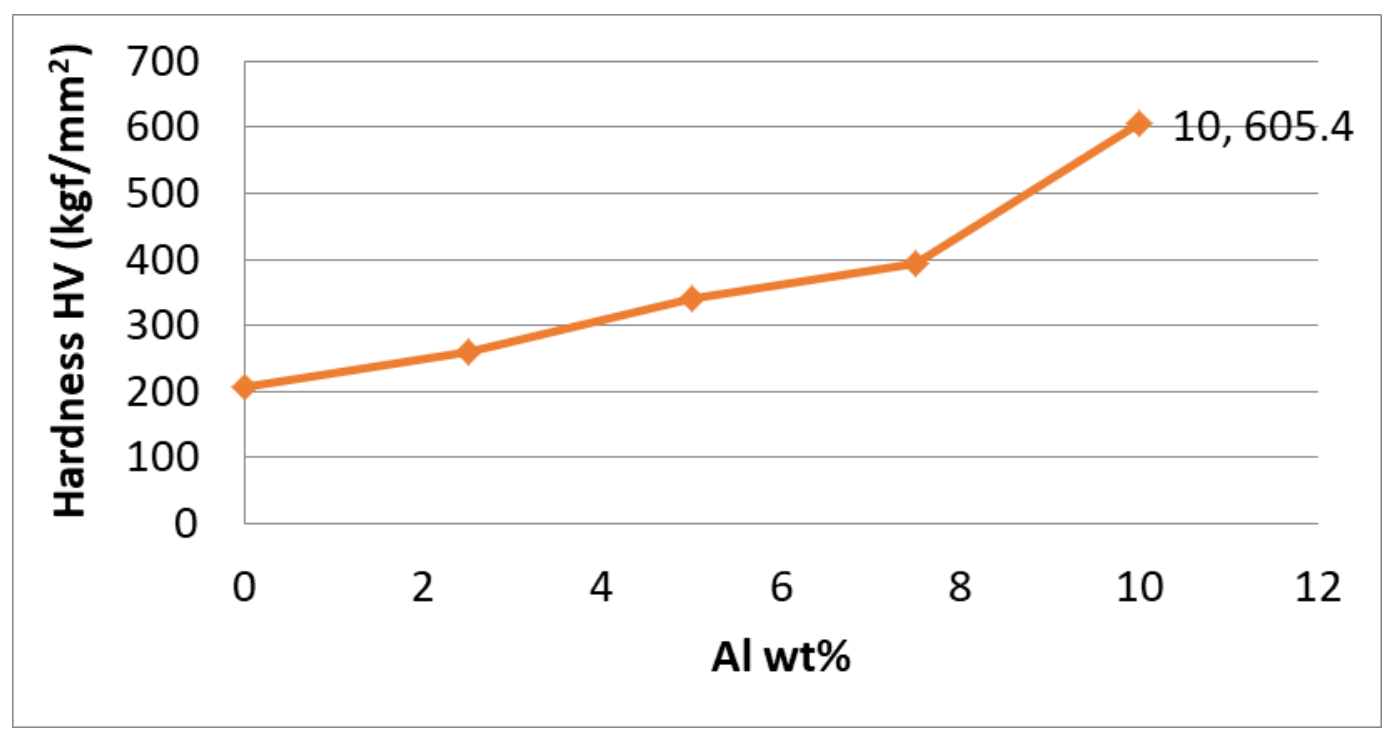

Fig. (6) Relationship between hardness and aluminum for casting brass.

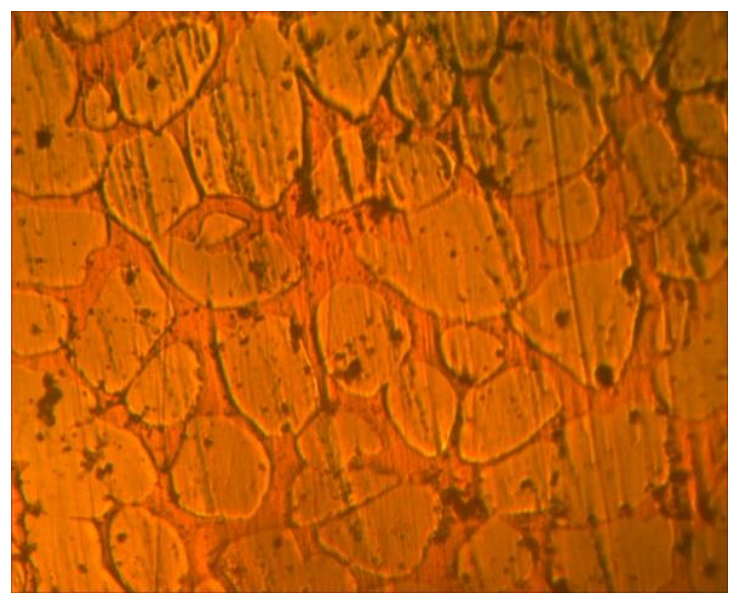

Casting brass alloy with $\mathrm{Al}$ of $2.5 \%$

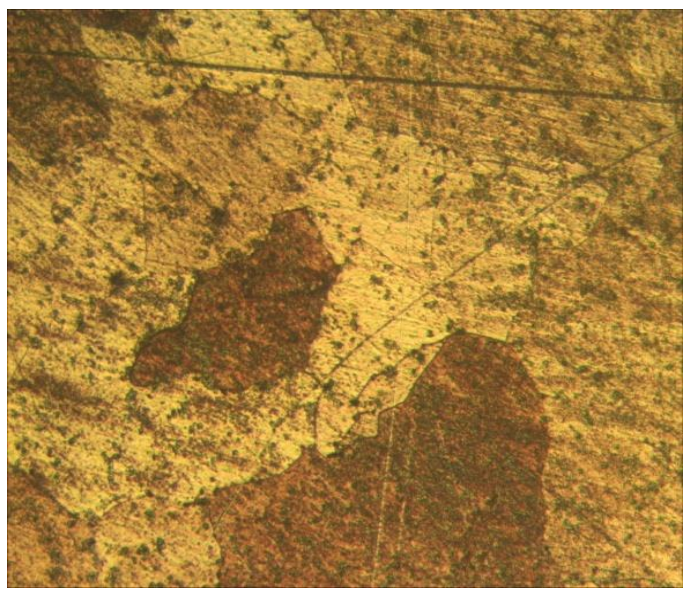

Casting brass alloy with $\mathrm{Al}$ of $5 \%$

Fig. (7) Microstructure of casting brass alloy with Al\% of 2.5 and 5\% (X1600).

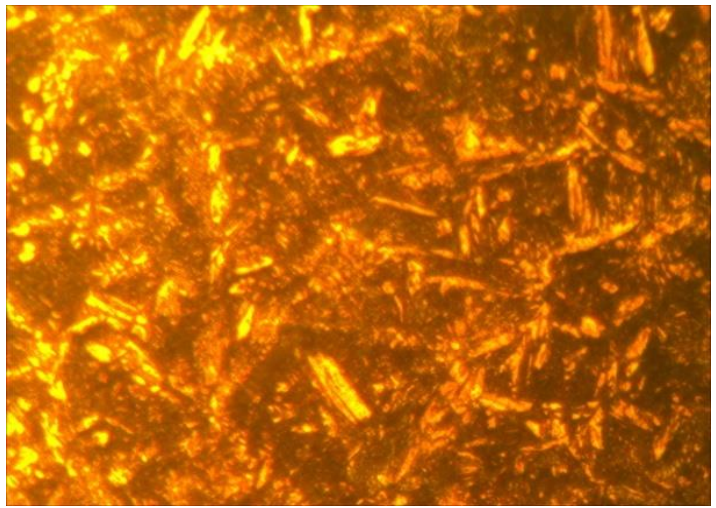

Casting brass alloy with $\mathrm{Al}$ of $7.5 \%$

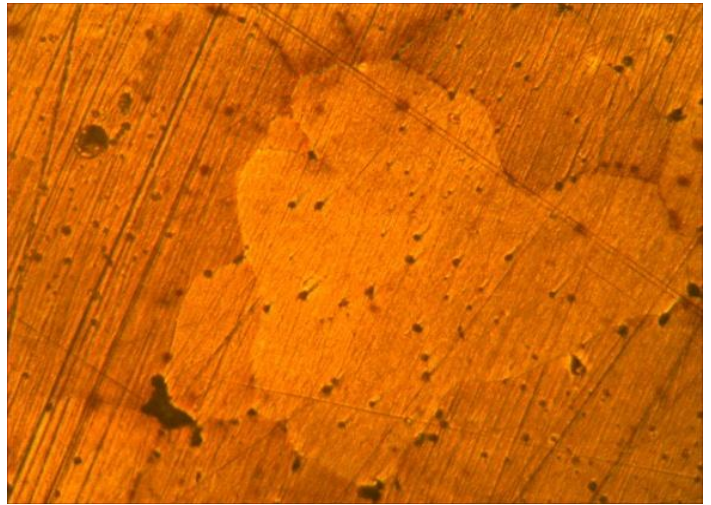

Casting brass alloy with $\mathrm{Al}$ of $10 \%$

Fig. (8): Microstructure of casting brass alloy with A1\% of 7.5 and 10\% (X1600). 


\section{REFERENCES}

A Arisgraha, I Angela, N A Arandana, and B T Sofyan, Effects of aluminum addition on the characteristics of $\mathrm{Cu} 28 \mathrm{Zn}$ brass produced by gravity casting, IOP Conf. Series: Materials Science and Engineering 285 (2017) 012031.

James Michel, Introduction to copper and copper alloys, Copper development association Inc., Copper Alliance, 2013,

https://www.copper.org/publications/pub_list/pdf/introduction-to-copper-and-copper-

alloys.pdf.

Kommel L, Hussainova I and Volobueva O, Microstructure and properties development of copper during severe plastic deformation. Materials \& Design, Vol. 28, pp. 2121-8, 2007.

Kosan industries private limited, Oxygen cylinder valve, https://www.indiamart.com/proddetail/oxygen-cylinder-valve-7327701648.html

M. Kondracki, J. Gawronski and J. Szajnar, The alloy additions influence on technological properties of fixture brasses, 12th international scientific conference: Achevements in mechanical and materials engineering, Conference proceeding, AMME2003, pp. 485-490, 2003.

Muna K. Abbass, Effect of Aluminum addition on some mechanical properties of Alpha -Brass 70/30, JIMEC conference 2001, Volume 1, Jordan Engineers Association, 2001.

Nowosielski R., Ductility minimum temperature in selected mono-phase, binary brasses, Journal of Materials Processing Technology. Vol.109, pp.142-53, 2001.

Rajab M. Hussein and Osama I. Abd, Influence of $\mathrm{Al}$ and $\mathrm{Ti}$ addition on microstructure and mechanical properties of leaded brass alloys, Hindawi publishing corporation: Indian journal of materials science, 2014.

Sujit Kumar Jha, Devibala Balakumar and Rajalingam Paluchamy, Experimental analysis of microstructure and mechanical properties of copper and brass-based alloys, International Journal of Automotive and Mechanical Engineering (IJAME), Volume 11, pp. 2317-2331, 2015

Zhuangzhuang Dong, Jinchuan Jie, Bowen Dong, Xianlong Wang, Effect of aluminum addition on microstructure and properties of a novel nickel-silicon-containing brass, Journal of materials research, Volume 35, Issue 12, pp. 1598-161, 2020. 